\title{
The Application of Blended Learning in Training Primary School English Teachers in Xi' an
}

\author{
Runxia Cao
}

School of Foreign Studies, Xi' an University, 710065

Keywords: Blended learning; Xi'an primary school; English teachers; Training

\begin{abstract}
With the development of educational technology, the traditional classroom teaching mode has been gradually replaced by blended learning mode. This kind of blended educational approach can be applied not only to students' learning but also to the training of teachers. In recent years, the demands for English teacher training in Xi'an primary schools have been on the rise, and the training of English teachers in local primary schools has received unprecedented attention. In the process of actively carrying out teacher training, the education department hopes to conduct more comprehensive trainings in Xi'an urban and rural primary schools to make better improvements. Therefore, it is of significance to explore the application of blended learning in training primary school English teachers in Xi'an, hence to improve their teaching and researching quality.
\end{abstract}

\section{Introduction}

Recently, the establishment of primary English curriculum has been paid much more attention. Therefore, striving to build an excellent primary school English teacher team is the key and assurance to promote the success of primary English curriculum establishment. The further improvement of the quality of primary English teachers depends on high quality teacher training. With the continuous deepening of curriculum reform, the training of primary English teachers is paid more and more attention by the relevant departments. The provincial and municipal governments are gradually increasing the training of English teachers of primary schools, but the effect is not obvious. The key reason is the lack of the clear teacher training objectives and subjective initiatives. Secondly, the single form of training and the lack of targeted training contents also greatly reduce the effectiveness of training. In view of the above situation and the characteristics of the work of primary English teachers, applying blended learning to the training of primary English teachers is a new idea provided by the construction of educational information for the innovation of teacher training.

\section{The Connotation and Function of Blended Learning}

\section{The connotation of blended learning}

Blended learning (B-learning) is a learning method to apply "appropriate" learning techniques and "appropriate" learning styles at the "appropriate" time, passing "appropriate" abilities to "appropriate" learners, thus to obtain the optimized learning effect. Blended learning is a kind of learning way, which is formed by people's deep reflection on the traditional classroom face-to-face teaching and distance-based online learning. The starting point of the theory lies in the combination of "face-to-face teaching" and "online learning". At present, blended learning has been frequently used in enterprise training, higher education, primary and secondary educations and teacher's continuing education.

\section{The function of blended learning}

Blended learning can make learning more convenient and achieve good learning effects. In the training process of primary school English teachers, because of the actual level and the weakening of synchronicity among teachers, the blended learning mode can meet the needs of teachers with different levels of learning to better improve work efficiency in the process of unified content training. The blended learning helps teachers to adopt a combination of self-study and teacher intervention in the process of synchronized training in order to achieve better training results. 


\section{The Theoretical Basis of Blended Learning Applied to Teacher Training}

\section{The developing rule of teacher's professionalization}

The so-called teacher's professionalization refers to continuous professional training to achieve the effect of lifelong learning in the teacher's entire career development process as the teacher's professionalization is based on the constantly changing basis of the learning content and learning patterns, and based on the students' learning accomplishment and the continuous improvement of the overall level. Therefore, teachers must gradually acquire the progressive knowledge of the education profession, and continuously advance the knowledge and skills of education in the professional practice of education. Therefore, the process of teachers' professionalization is an inevitable requirement on the way of specialization of education professionals. It is one of the objectives of teacher education and training that Xi'an Education Departments attach great importance to, so as to enhance the diversified construction of organizations in various fields such as professional knowledge and skills and to promote the comprehensive level of primary English teachers in their posts. The combination of teachers' professionalization and blended learning gives much inspiration to the training of English teachers of primary schools in Xi'an.

\section{Learning theory of constructivism}

Constructivism is a theory of knowledge and learning. Constructivism emphasizes the initiative of learners. It is assumed that learners must create new meanings based on the original knowledge and experience and on the basis of the fragmentation of original knowledge and experience. Learning is the process of the learner's sublimation of the original knowledge. And this sublimation is often done in the social and cultural interaction. Constructivism theory can well promote the remodeling of the new English teacher training concept in connection with the training of primary English teachers. For English teachers of primary schools, especially non-English majored primary English teachers, their learning process is often directed at the basic grammar of English and phonetic pronunciation. In the process of re-construction of English teaching methods and a series of knowledge related to English education, many teachers tend to innovation to study more innovative and more adaptable educational methods to students.

\section{The Application of Blended Learning in Training Primary School English Teachers}

\section{Several models of blended learning}

\section{Blended learning mode of John's four basic stages}

Each person's learning competence is different, and when making and defining learning needs, it should be intuitively determined based on the actual characteristics of the individual.

The learning plans should be developed according to the learner's actual learning characteristics, and the general characteristics and measurement strategies related to the final ability should be understood. Developing learners' characteristics needs to choose a very suitable learning strategy for learners.

According to the blended learning environment, the traditional method of face-to-face education and online learning are fully and optimally combined with the choice of development and learning content, time constraints, computer configuration standards, learning management systems and metrics.

In the final training phase, all blended learning results are aggregated together so that students' learning can be measured to determine if their intended learning goals have been met.

\section{Rochester's design of blended learning}

Blended learning is divided into traditional face-to-face teaching and online teaching, which believes that in the face-to-face teaching and learning process, if the teacher's teaching is accompanied by a speech and statement, then the use of educational resources are actually paper resources, and these teaching resources will be accompanied by speeches and statements as well as teaching evaluation behavior. Teaching behavior combined with traditional online teaching can make the teachers to discuss between groups, and the most discussed way can be occupied about $25 \%$ to $50 \%$, which can take online learning approach, with the use of virtual team, project 
summary and other methods, thus to conduct equality and non-synchronous discussion and exchange.

\section{The application of blended learning in training primary school English teachers}

Li Ke-dong's eight blended learning modes can be used to establish a comprehensive interaction and cooperation training model of primary school English teacher. The establishment of a blended learning mode in primary English teacher training can first determine the objectives of blended learning, determine the expected results of blended training, and select the media and circulars to be delivered, combine with the traditional teaching and learning methods and online activities of mobile terminals and strengthen the connectivity of training and self-evaluation. At the same time, according to the design of course specialists, the entire training process should be well designed to confirm the completion of blended teaching and learning and what kind of knowledge tactics should be used for better training progress. In the implementation of the observation stage and design and the implementation planning process, all the training programs should be observed and recorded, and the final results of their training should be understood. In the training, the combination of self evaluation and preceptor evaluation can be taken for the evaluation of learning effectiveness.

\section{Design and Implementation of Xi'an Primary School English Teacher Training Program Based on Blended Learning}

\section{Design of primary school English teacher training program in Xi'an}

The design of the entire program is roughly divided into eight steps:

Training teachers should be selected as close as to the stage of learning and the teacher. As the main body of the same training content, each training plan and time should be as uniform as possible.

The specific guiding ideology of the whole training program is to hopefully improve the actual level of primary school English teachers in Xi'an. These practical levels should be gradually improved in the process of teaching and researching, not just to promote teachers' personal levels, but also should include the progress of teaching mode and teaching method.

Under the mission of deciding the driving force of the task and the activity of the training content, the instructor carries out autonomous learning and collaborative learning.

Through the sub-group of collaborative learning of the primary school English teachers in Xi'an, combined with individual self-learning, traditional teaching methods and online classroom information sharing methods are used to complete the combined teaching content.

Teaching content is conducted in multimedia classroom, which is easy to group and individual learning and can be synchronized.

The individual learning and e-learning can be combined with the help of online learning platform.

In the traditional face-to-face learning process, teaching analysis can be done on the effect of teaching and the process of the course. With the support of the media, face-to-face activities of the activity center can be carried out, and face-to-face teaching and learning evaluation can be conducted.

With the process of online learning, teaching analysis can also be carried out at the same time. However, this teaching decomposition focuses more on media teaching and media support as well as the sharing of teacher resources. Through the exchange of online activities, we can solve some learning processes that are not synchronous across regions and time. In addition, the teaching evaluation should be divided into two parts. Combining with face-to-face learning and online learning, the grades of the two aspects are the final results as the basis for the final training evaluation.

\section{Implementation of primary school English teacher training program in Xi'an}

Stage training is carried out according to the time and place of Xi'an primary school English teachers.

According to the time and region, stage training evaluation mechanism of primary school English teachers in Xi'an is established. Based on the evaluation method of online evaluation and 
face-to-face evaluation, the final training results of primary school English teacher are synthetically evaluated and included in the teacher evaluation results.

The appropriate paper materials and online materials are selected, and it is advocated to share the resources among teachers.

A combination of network resources and training courseware is adopted, and the key point is to share actual case resources of teachers' educational resources and teaching courses and share dynamic teaching experience and teaching process resources.

A cohesive, blended learning mode and sharing structure is established that includes face-to-face interviews with resource support and sharing, case studies, writing studies and discussions, especially lectures and meticulous discussions during the exchange and cooperation process. At the same time, it is necessary to combine the online teaching with the combination of independent learning and writing learning, and establish the blended learning structure of the three-dimensional network of online teaching and writing learning.

\section{Conclusion}

The training of Xi'an primary school English teachers should be a purposeful and direct exchange process. This important training and education mechanism requires learners to take the initiative to digest the training contents. Teachers are not the transfer stations of information, but should take the initiative to construct knowledge and development skills, and become the subject of professional teaching skills. Through the learning and collaboration brought by the blended learning mode, teachers can help themselves to solve the problem of how to build a reasonable knowledge structure, how to better understand the knowledge framework and reasonably construct the knowledge content to a trinity mechanism in the process of primary school English teacher training. The training content of primary school English teachers should be based on the original knowledge of English teachers. In combination with their specific teaching experiences, it is necessary to actively reflect on its professional needs and teaching needs. In the process of training and reforming the primary school English teachers in Xi'an, we advocate that we should actively solve the teaching problems in an individual or team manner in order to achieve the original teaching and research results.

\section{Acknowledgements}

Fund Project: The Application of Blended Learning in Training Primary School English Teachers in Xi'an-Taking the "Training Plan" of Xi'an University as an Example (No.EIJYB2017-090)

\section{References}

[1] Wang X.D.: Applied research on blended learning in primary English teaching [J]. Digital Teaching in Primary and Secondary Schools, 2017 (01): 33-35. In Chinese.

[2] Zhong Y.Q.: The application of Kirkpatrick model into evaluating blended teaching of college English [J]. Journal of Hangzhou Dianzi University (Social Sciences), 2017, 13(02): 74-78. In Chinese.

[3] Hu Z.Y.: The application of blended learning mode in primary English classroom [J]. College Entrance Examination, 2016(24): 66. In Chinese.

[4] Zeng W.N.: Research on blended learning in elementary English supported by "Internet +" [J]. China Information Technology Education, 2016(05): 17-19. In Chinese.

[5] Guan M.: Application analysis of blended learning mode in primary English teaching [J]. Xinkecheng, 2015(12): 86. In Chinese.

[6] Du S.C. and Fu Z.T.: The development and the main problems of blended learning [J]. China Higher Education Research, 2016(10): 52-55+92. In Chinese.

[7] Zhang Y.Q.: Study on the application of blended learning mode in primary English teacher training [D]. Qufu Normal University, 2013. In Chinese.

[8] Hsu C.L.: Study on the application of blended learning mode in primary English teaching [D]. 
Qufu Normal University, 2008. In Chinese.

[9] Kamolbhan Olapiriyakul, Julian M. Scher. A guide to establishing hybrid learning courses:

Employing information technology to create a new learning experience, and a case study [J]. The Internet and Higher Education, 2006, 9(4).

[10] Guodong Zhao, Shuai Yuan. Hybrid Learning [M]. Springer Berlin Heidelberg: 2010-06-15. 